\title{
Erratum to: Unitariness, evidence and quality in bio-medicolegal sciences
}

\section{Santo Davide Ferrara $\cdot$ Heidi Pfeiffer}

Published online: 3 August 2010

(C) Springer-Verlag 2010

\section{Erratum to: Int J Legal Med}

\author{
DOI 10.1007/s00414-010-0477-x
}

An entry was incorrectly captured in the reference list. The corrected reference is given below:

\section{Reference}

1. Ferrara SD, Bajanowski T, Cecchi R, Snenghi R, Case C, Viel G (2010) Bio-medicolegal guidelines and protocols Survey and future perspectives in Europe. Int J Leg Med 124:345-350

The online version of the original article can be found at http://dx.doi. org/10.1007/s00414-010-0477-x.

S. D. Ferrara $(\bowtie)$

Forensic Toxicology and Antidoping,

University-Hospital of Padova,

Via Falloppio 50,

35121 Padova, Italy

e-mail: santodavide.ferrara@unipd.it

H. Pfeiffer $(\square)$

Institut für Rechtsmedizin, Westfälische Wilhelms-Universität,

Röntgenstrasse 23,

48149 Münster, Germany

e-mail: pfeiffh@uni-muenster.de 